\title{
CONSTRUINDO A SUBJETIVIDADE POĹTICA: CONTRIBUIÇÕES PARA PENSAR A UNIVERSIDADE COMO ESPAÇO DE FORMAÇÃo
}

\begin{tabular}{c}
\hline CONSTRUYENDO LA SUBJETIVIDAD POLÍTICA: \\
CONTRIBUCIONES PARA PENSAR LA UNIVERSIDAD COMO ESPACIO DE FORMACIÓN \\
\hline CONSTRUCTING THE POLITICAL SUBJECTIVITY: \\
CONTRIBUTIONS TO THINK UNIVERSITY AS A FORMATIVE SPACE
\end{tabular}

\section{Claudete Lampert Gruginskie ${ }^{1}$ Maria Elly Herz, Genro ${ }^{2}$ Bernardo Sfredo Miorando ${ }^{3}$}

RESUMO: Neste artigo, exploramos o conceito de sujeito político, abordando os aportes dos sujeitos que atuam nos espaços de formação universidade e movimento social. Discutimos esses aportes com referências teóricas que objetivam dar uma maior densidade à ideia de subjetividade política democrática. Para tanto, destacamos a importância da universidade pública como espaço de formação política e construção de cidadania. Utilizamos como fontes de dados o conteúdo das falas de estudantes e egressos engajados em movimentos sociais. Concluímos que as experiências vividas em espaços de formação produzem, através da reflexão coletiva, uma compreensão do espaço social que possibilita transformá-lo pela ação. A formação política experienciada no deslocamento entre movimento social e universidade potencializa os sujeitos que reivindicam direitos a partir de lutas comuns, desenvolvendo o espaço público como expressão de um sujeito político potente.

PALAVRAS-ChAVE: Universidade pública. Sujeito político. Educação política.

ABSTRACT: In this article, we explore the concept of political subject, approaching the inputs from subjects who act in the formative spaces university and social movement. We discuss such inputs with theoretical references that aim to increase the density of the idea of democratic political subjectivity. For this purpose, we highlight the public university as a space for political education and citizenship construction. We use as data sources the content of the speeches of students and graduates engaged in social movements. We conclude that experiences lived within formative spaces produce, through collective critical reflexion, the understanding of the social space that allows them to transform it by action. Political education articulated between social movement and university potentiates the subjects who reclaim rights from common struggles, developing the public space as an expression of a potent political subject.

KEYWORDS: Public university. Political subject. Political education.

RESUMEN: En este artículo, exploramos el concepto de sujeto político, abordando los aportes de sujetos que actúan en los espacios de formación universidad y movimiento social. Discutimos eses aportes con referencias teóricas que objetivan dar mayor densidad a la idea de subjetividad política democrática. Para tanto, destacamos la importancia de la universidad pública como espacio de formación política y construcción de ciudadanía. Utilizamos como fuentes de datos el contenido de hablas de estudiantes y egresados engajados en movimientos sociales. Concluimos que las experiencias vividas en espacios de formación producen, a través de la reflexión colectiva, una comprensión del espacio social que posibilita transformarlo por la acción. La formación política

Submetido em: 26/06/2018 - Aceito em: 08/10/2018 - Publicado em: 24/01/2019

\begin{tabular}{l|c|c|c|c|c|c|} 
(C) Rev. Educ. Perspec. & Viçosa, $M G$ & v. 9 & n. 3 & p.734-749 & set./dez. 2018 & eISSN 2178-8359 \\
\hline
\end{tabular}


articulada entre movimiento social y universidad potencializa los sujetos que reivindican derechos a partir de luchas comunes, desarrollando el espacio público como expresión de un sujeto político potente.

PALABRAS CLAVE: Universidad pública. Sujeto político. Formación política.

\section{INTRODUÇÃO}

O Brasil do século XXI, especialmente de 2003 a 2014, foi palco de diversos processos de mudanças na educação superior. A expansão da oferta, combinada a políticas de democratização do acesso como as ações afirmativas (Lei $\mathrm{n}^{\circ}$ 12.711/2012) (BRASIL, 2012), permitiu o ingresso de sujeitos historicamente excluídos da educação superior, ou seja, estudantes de escola pública, de baixa renda, pretos, pardos e indígenas. Para Ristoff (2016, p. 60), essa "expansão com inclusão" leva a naturalizar "a demanda por educação superior para contingentes mais expressivos da sociedade brasileira, colocando as energias criativas derivadas deste processo a serviço do desenvolvimento do país". Tais energias se desencadeiam no confronto desses estudantes com a estrutura tradicional da universidade, uma vez que "trazem para a arena acadêmica a diversidade de experiências de vida que, até pouco, se encontravam somente do lado de fora" (DOEBBER, 2017, p. 42).

Esses públicos podem provocar tensionamentos em processos e estruturas acadêmicas de modo a ensejar modificações na cultura política das instituições de educação superior. Grisa (2015) aponta debates e mudanças legislativas que ocorrem pela inclusão de pautas progressistas nas instâncias administrativas, servindo como fundamentos para uma "cultura do reconhecimento". Os atores sociais envolvidos nesses processos constituem subjetividades políticas, com o reconhecimento de suas identidades e de suas lutas. Nesse movimento do sujeito,

[...] elabora-se estratégias de conformismo e resistência, passividade e rebelião, segundo os agentes com os quais se defronta. Isso tudo porque ocorre a identificação do processo de ocultamento das diferenças sociais existentes e, consequentemente, a identificação dos distintos interesses de classe presentes (GOHN, 1994, p. 19).

A educação superior, problematizando conhecimentos, pode promover o desocultamento de estruturas de opressão e apresentar aos sujeitos alternativas de incidir na cena pública. Um desdobramento possível é a participação política no reforço de processos democráticos como estratégia para viabilizar a reversão das múltiplas formas de exclusão e opressão existentes na sociedade. Isso se materializa "no cotidiano através do processo de identidade políticocultural que as lutas cotidianas geram" (GOHN, 1994, p. 17).

Neste artigo, tematizamos o conceito de sujeito político considerando as contribuições dos sujeitos na universidade e nos movimentos sociais (MS) para o fortalecimento de uma

\begin{tabular}{l|l|l|l|l|l|l} 
(C) Rev. Educ. Perspec. & Viçosa, $M G$ & v. 9 & n. 3 & p.734-749 & set./dez. 2018 & eISSN 2178-8359 \\
\hline
\end{tabular}


subjetividade política democrática. Para tanto, partimos de uma concepção de política para explorar entendimentos de estudantes universitários engajados em MS, vislumbrando a potencialização da ação política pela participação nesses espaços.

Este trabalho destaca as contribuições desses sujeitos e suas experiências para repensar a universidade, mobilizando a categoria do sujeito político. Repercutir essas vozes nos permite construir novos recursos interpretativos na sustentação de novas práticas, mais democráticas. Ativá-las para produzir conhecimento afirma a legitimidade de sujeitos historicamente subalternizados. $\mathrm{O}$ artigo científico, visibilizando essas experiências, carrega o potencial formativo de fortalecer a democracia no debate acadêmico.

\section{PENSANDO A POLÍTICA: CONTRIBUIÇÕES DA UNIVERSIDADE PARA A FORMAÇÃO DE SUBJETIVIDADES DEMOCRÁTICAS}

Abordamos aqui a política na perspectiva de Arendt (2013), que resgata seu sentido radical das formas de organização do convívio coletivo na pólis grega, como inspiração para o aprofundamento da democracia. Para a autora, a política surge no espaço de relação entre as pessoas, "como um meio para um fim mais elevado" (ARENDT, 2013, p. 45). Considerando o indivíduo um ser social, portanto, interdependente em relação aos outros seres humanos, a política emerge como possibilidade de ordenação da vida humana como convivência entre os diferentes. Por estar ligada ao coletivo, a política também se relaciona diretamente ao espaço público: o espaço da liberdade e da ação, o espaço do plural, da construção coletiva através do diálogo. O espaço público é também o espaço dos consensos, ainda que provisórios (GENRO, 2011), o que reafirma a importância da constante reconfiguração do agir em conjunto.

Arendt (2013) chama a atenção para a desconfiança que acompanha a prática política desde a antiguidade e que, na contemporaneidade, manifesta-se na tentação de aboli-la, substituindo-a pelo controle técnico da burocracia. A preocupação com a democracia envolve a disposição para construir instituições que garantam a possibilidade de que as pessoas se rebelem contra ordens de dominação - o que se faz através da ação (ARENDT, 2007). A subjetividade política democrática age justamente na resistência às formas políticas - e supostamente apolíticas, tecnoburocráticas - opressivas, instituindo, garantindo e fortalecendo espaços públicos de presença, expressão e representação que ampliem os horizontes de participação, conflito e diálogo.

Em Mouffe (2001, p. 21), encontramos o referencial de sujeito político na perspectiva de uma democracia pluralista em que os antagonismos se transformam em agonismos:

\begin{tabular}{l|l|l|l|l|l|l} 
(C) Rev. Educ. Perspec. & Viçosa, $M G$ & v. 9 & n. 3 & p.734-749 & set./dez. 2018 & eISSN 2178-8359 \\
\hline
\end{tabular}


Daqui decorre a importância de se distinguir entre dois tipos de relações políticas: uma de antagonismo entre inimigos, e uma de agonismo entre adversários. Nós podemos dizer que o objetivo da política democrática é transformar o antagonismo em agonismo.

Nesta perspectiva, afirma Genro (2011, p. 143), é condição para uma democracia pluralista "transformar antagonismo em agonismo, ou seja, tornar legítimo o embate de ideias abrindo espaço para a negociação de consensos provisórios". A autora afirma, ainda, que a educação tem papel importante neste processo, "mas isso pressupõe formação de sujeitos que tenham propriedade, certa consistência no jogo argumentativo, na disputa política de diferentes significados e projetos sociais e políticos" (GENRO, 2011, p. 144).

Para Mouffe (2001, p. 18), é preciso entender que "o político não é algo que tem uma localização específica, determinada, na sociedade e que todos os tipos de relações sociais podem tornar-se palco de conflitos políticos". A universidade como instituição da esfera pública, apresenta-se como um desses espaços, onde a diversidade se faz representar. A democracia pluralista reconhece a diversidade como parte do processo político.

Essa compreensão de política permite reconhecer as exclusões a que historicamente foram submetidos grupos sociais subalternizados e feitos minorias. Esses grupos, ao lutarem por reconhecimento e se colocarem na cena política como agentes e sujeitos de transformação social, elegem a universidade como uma de suas arenas. Seus movimentos permitem também perceber a complexidade da estrutura social e reconhecer a legitimidade das diferentes bandeiras de luta e a multiplicidade de demandas que permeiam as relações sociais. Chamam a atenção para a necessidade de constituir um novo tipo de sujeito na universidade, com uma perspectiva de justiça, democracia e de participação - um sujeito político potente.

Esta identidade público-política do sujeito o transforma em agente social, que, mergulhado no tecido social, atua em todos os espaços ocupados, sendo reconhecido publicamente em seus diálogos, posturas, interações, e influindo na definição de políticas. Gohn (2012, p. 113) considera

[...] 'sujeito' uma categoria fundamental, que constitui e posiciona indivíduos na história dos processos sociais, culturais e políticos de uma sociedade. Ela confere protagonismo e ativismo aos indivíduos e grupos sociais, transformando-os de atores sociais, políticos e culturais em agentes de seu tempo, de sua história, de sua identidade, de seu papel como ser humano, político, social.

Aqui, a capacidade de agência está na competência para propor alternativas factíveis de ação, afinal uma democracia pluralista "requer a criação de identidades coletivas ao redor de posições diferenciadas bem como a possibilidade de escolha entre alternativas reais" (MOUFFE, 2001, p. 22). Na sociedade brasileira contemporânea, a universidade é um lugar em que essa capacidade vai se refinar, onde os sujeitos políticos adquirem novas competências discursivas e estratégias de ação com as quais vão compondo projetos mais

\begin{tabular}{l|l|l|l|l}
\hline & n. 3 & p.734-749 \\
\hline
\end{tabular}

set./dez. 2018 eISSN 2178-8359


amplos. Portanto, para potencializar a democratização de nosso país, consideramos necessário fortalecer a universidade como espaço privilegiado de experiências de diálogos, de participação e de construção da cidadania.

A universidade tem um papel político fundamental de formar para a ação na pólis. A intencionalidade de suas proposições é determinante para a manutenção ou a transformação das estruturas sociais (RIBEIRO, 1969). Uma formação política resulta necessariamente do diálogo com a realidade, com as práticas sociais e leva a uma tomada de consciência e à ação transformadora (SEVERINO, F., 2011). A universidade seguindo seu curso espontâneo tende a manter as estruturas sociais. Porém, existem

[...] conjunturas sócio-culturais nas quais se gera uma consciência crítica que leva a universidade a repensar-se e a propor-se mudanças profundas que permitam romper a estrutura cristalizada, eliminar seus conteúdos mais anacrônicos e alcançar uma forma nova e viável (RIBEIRO, 1969, p. 35).

A universidade, como espaço formativo, precisa considerar lutas e transformações sociais, constituindo-se em lócus do debate democrático, da inclusão, da diversidade, no exercício da cidadania. Nesta perspectiva, Severino, A. (2012, p. 22) destaca que: "para além do preparo epistêmico e técnico, a formação universitária, tendo em vista garantir a formação integral do homem, precisa assegurar o desenvolvimento das sensibilidades política, ética e estética das pessoas". Neste sentido, Severino, F. (2011, p. 20) afirma que:

\begin{abstract}
A política remete a educar com diálogo, na práxis, na justiça e na liberdade. Nesse contexto, educação, ética e política se apresentam como agentes para o desenvolvimento de uma visão crítica do mundo, estabelecendo condições e possibilidades para a compreensão das exigências de uma formação que é técnica e política, mediatizada pela ética, viabilizadora de uma prática pedagógica consciente.
\end{abstract}

Este estudo nos provocou a pensar a formação de uma subjetividade política democrática, considerando a universidade e o movimento social como espaços que podem promover essa construção.

\title{
EXPLORANDO ESPAÇOS DE FORMAÇÃO: CAMINHOS DA PESQUISA E AS VOZES DOS SUJEITOS
}

A pesquisa que originou os resultados aqui apresentados foi conduzida através de uma abordagem qualitativa (MINAYO, 2012), como um estudo exploratório (GIL, 2008). Os sujeitos da pesquisa foram estudantes e egressos da Universidade Federal do Rio Grande do Sul (UFRGS) engajados em movimentos sociais. A UFRGS é um dos critérios de delimitação dos sujeitos abordados na pesquisa. Ela nos é relevante, entre outras razões, por ser nosso espaço de estudos e trabalho, e por ser uma universidade grande e tradicional, de referência

\begin{tabular}{l|c|c|c|c|c|c|} 
(C) Rev. Educ. Perspec. & Viçosa, $M G$ & v. 9 & n. 3 & p.734-749 & set./dez. 2018 & eISSN 2178-8359 \\
\hline
\end{tabular}


em nosso país, o que torna interessante investigar a presença desse "novo" e desse "em movimento" que os sujeitos representam.

O material empírico aqui apresentado é resultado de entrevistas semiestruturadas com sete sujeitos. Os participantes foram selecionados entre estudantes e egressos da graduação e da pós-graduação da UFRGS, reconhecidos na comunidade universitária como referências dos movimentos negro, de mulheres, indígena e de lésbicas, gays, bissexuais e travestis, transexuais ou transgêneros (LGBT). A maior parte dos sujeitos está ligada à área de Educação, havendo também conexões com as áreas de Artes Visuais, Economia, Ciência Política e Ciências Sociais. Atribuímos a cada um dos sujeitos um pseudônimo, com o qual apresentamos suas falas ao analisá-las nesse artigo.

Exploramos o conteúdo das entrevistas por meio de uma análise qualitativa dos dados coletados na perspectiva que Gomes e colaboradores (2005) denominam "Método de Interpretação de Sentidos" caracterizada como "um caminho de análise de significados dentro de uma perspectiva das correntes compreensivas das ciências sociais que analisa: (a) palavras; (b) ações; (c) conjunto de inter-ações; (d) grupos; (e) instituições; (f) conjunturas, dentre outros corpos analíticos" (GOMES et al., 2005, p. 202).

Neste artigo, destacamos as percepções dos estudantes acerca da constituição do sujeito político e de espaços de formação em que isso ocorre: o movimento social e a universidade. Apresentamos, em duas subseções, trechos das entrevistas que permitem refletir, primeiramente, sobre o que é o sujeito político e, na sequência, sobre sua circulação entre os espaços da universidade e do movimento social. Na interpretação dessas falas, articulamos o referencial teórico para iluminar categorias que emergem como constituintes do movimento que os sujeitos operam em seu fazer político.

\section{O sujeito político: diálogo e sensibilidade em movimento}

O sujeito político que afirmamos aqui é capaz de pensar e tem autonomia para agir em conjunto, pelo bem coletivo, em uma perspectiva de cidadania democrática. Portanto, trata-se do sujeito - individual ou coletivo - que age considerando a política como processo e resultado da inter-relação entre pessoas e grupos (ARENDT, 2013). Através das vozes dos sujeitos, percebe-se a emergência de núcleos de sentidos que compõem uma narrativa da constituição do sujeito político. Destacamos as palavras que representam esses núcleos nas falas reproduzidas a seguir.

Um sujeito político, eu acho que é o que é autônomo, [...] que tem ação na sociedade. Então, esse sujeito político pode ser uma pessoa, um militante, um dirigente, assim como sujeito político também pode ser um movimento. Então, um sujeito político pode ser individual, como também pode ser coletivo, mas que tem essa perspectiva de transformação social. Que questiona os padrões sociais, a 
cultura patriarcal, que questiona a concentração de renda, que questiona o capitalismo, o patriarcado (ROSE).

O sujeito político é aquele que vai atrás, [...] para manter, pra ter um diálogo, pra ter uma discussão, pra trazer a pauta da visibilidade pra dentro do movimento. Porque o sujeito político é aquele que tá sempre provocando e cutucando e fazendo aquele, digamos, o advocacy, o controle social, a busca sempre do que é melhor não só pra vida do sujeito, mas pra vida dum coletivo. Então, é pensar nesse coletivo, né? (BRENDA LEE).

Acho que é o sujeito que se dá conta do seu papel, de qual sua posição dentro dessas estruturas de poder, estruturas políticas que se formam a todo tempo. [...]. E saber [...] influenciar também nesse sistema, né? Poder trocar as peças de lugar de vez em quando, ou provocar umas trocas de lugar de vez em quando. [...] Tem uma força política de se dar conta de como tu promoves, quebras ciclos, cria, te recrias, crias outras possibilidades também (JEAN).

Sujeito político é aquele que atua, que se incomoda, que traz as suas inquietudes, que dialoga com outros grupos, que está aberto a não falar só da sua bandeira ou da sua luta. É um sujeito que tá disposto a expandir essas diversidades, a estar presente também nesses diálogos e é um sujeito atuante. Acima de tudo, é um sujeito que não fica só construindo teoricamente (DANDARA).

É a capacidade da ação política. O sujeito pra Ciência Política é o que tem capacidade de agir ou agenciar; ter uma pauta; se fazer presente no espaço público político. Esse é o sujeito, né? Então, nem todos serão sujeitos. Tem que ter essa capacidade (PAGU).

Todos nós somos políticos, só que depende pra quê, pra onde você pensa assim. Quando eu tô falando que tomei a opção de fazer da minha vida uma trajetória, se fosse pra fortalecer o meu povo, isso é uma decisão política. [...] E eu, eu acredito muito, numa escola, por exemplo, onde eu trabalho, que vá trabalhar com o ser humano. [...] Que ele seja capaz de tomar suas decisões, que ele seja capaz de refletir sua vida, que ele seja capaz de refletir a sociedade em que ele vive, que ele seja capaz de tomar medidas que sejam favoráveis ao seu grupo (SEPÉ).

O sujeito político é aquele que produz política, é aquele que interage com a política e pensa que a política pode ser uma consequência e não apenas um exercício individual, no plano denunciatório, no plano diagnóstico. Porque a política, ela tem que ter consequência, quer dizer, as ações tuas têm que ter consequência. [...] E ela tem que ser temporal, e ela tem que dialogar com as condiçõos objetivas históricas dadas. [...] E a força nossa de modificar o comportamento do Estado (MARTIN).

Ao considerarmos o que dizem os sujeitos, articulamos fragmentos de suas narrativas no que pode ser considerado um percurso de construção da subjetividade política. Essa subjetividade existe inicialmente como potencialidade ("todos nós somos políticos"), presente em todo ser humano, mas dependente de um clinâmen ("depende para quê"). A essa potencialidade, associa-se uma condicionalidade ("tem que ter essa capacidade"), uma competência para irromper como ator em uma arena de disputas ("se fazer presente no espaço público político").

\begin{tabular}{l|l|l|l|l|l|l} 
(C) Rev. Educ. Perspec. & Viçosa, $M G$ & v. 9 & n. 3 & p.734-749 & set./dez. 2018 & eISSN 2178-8359 \\
\hline
\end{tabular}


O que, então, torna um indivíduo um sujeito político? Há aqui uma primeira dimensão de sensibilidade, capacidade de se afetar pelo que se passa no mundo ("se incomoda") na medida em que os acontecimentos interagem com suas expectativas e crenças ("eu acredito muito"). A partir daí, desenvolve-se uma forma específica de consciência que associa a autorreflexividade ("refletir sua vida") e uma leitura de mundo ("estruturas políticas que se formam a todo tempo", "plano diagnóstico", "dialogar com as condições objetivas históricas dadas") em um pensamento estratégico que localiza o sujeito em uma teia de relações de poder ("se dá conta do seu papel") que poderão ser acionadas ("provocar umas trocas de lugar de vez em quando").

Essa politização da consciência desemboca então na ação no mundo ("tem ação", "ação política", "sujeito atuante"). Ela se sustenta de critérios como autonomia moral ("é autônomo"), como o questionamento ("que questiona", "plano denunciatório"), e passa pela apetência pelo conflito ("tá disposto", "tá sempre provocando"). Há aqui uma disposição para a intencionalização política das vivências ("fazer da minha vida uma trajetória") que pode ser direcionada em objetivos altruístas ("transformação social", "pra vida dum coletivo", "fortalecer o meu povo", "tomar medidas que sejam favoráveis ao seu grupo"). Nesse sentido, o sujeito político também traz como elemento fundamental o recurso de potencialização no coletivo ("pode ser um movimento", "pode ser coletivo", "não apenas individual", "força nossa").

Portanto, para sua irrupção no espaço político com sua ação, o sujeito político ativa uma série de técnicas ("agenciar", "advocacy, o controle social”). Fundamental entre elas é o diálogo, seja em coletividades às quais já se pertence ("pra dentro do movimento"), seja com adversários ou possíveis aliados ("dialoga com outros grupos"). Outra das capacidades do sujeito político é tornar fenômenos aparentes na sociedade, fazendo deles questões públicas ("visibilidade", "bandeira", "ter uma pauta", "trazer a pauta"). Chega-se, então, ao horizonte em que a ação no espaço público se torna potência de intervenção nos processos e nas estruturas da política ("as ações tuas têm que ter consequência", "modificar o comportamento do Estado", "influenciar também nesse sistema”, "crias outras possibilidades também").

Arendt (2007) propõe que é pela ação que o sujeito produz novos começos. Os sujeitos da pesquisa parecem indicar que, dentro dessa categoria do novo, o sujeito político é também capaz de produzir novas formas de ação política e novas subjetividades políticas. Gohn (1994; 2012) entende que os sujeitos produzem sua capacidade de agência no desenvolvimento de repertórios de estratégias e de consciência sobre interesses em disputa. Essa disputa, aponta Genro (2011), supõe aptidão para jogos políticos em que se manejam não apenas discursos, mas composições de projetos. A democracia passa pela capacidade de revestir os debates com diferentes formas de legitimidade que, no pluralismo agonista de

\begin{tabular}{l|c|c|c|c|c|c|} 
() Rev. Educ. Perspec. & Viçosa, $M G$ & v. 9 & n. 3 & p.734-749 & set./dez. 2018 & eISSN 2178-8359 \\
\hline
\end{tabular}


Mouffe (2001), envolvem o reposicionamento do sujeito diante do conflito. Propomos que, implicitamente como fio condutor dessa construção da subjetividade política, está presente uma perspectiva de autotransformação ("te recrias", "expandir essas diversidades"). Entendemos que esses sujeitos políticos, estudantes universitários engajados em movimentos sociais, trazem em si uma forma específica de vida interior que denominamos de "movimento do sujeito".

\section{Espaços de formação: subjetividade política entre universidade e movimentos sociais}

A construção de uma subjetividade política depende, assim, de uma formação política. $\mathrm{O}$ processo de formação e os espaços através dos quais ela ocorre podem ser elementos de potencialização do sujeito e de seus movimentos. Os estudantes universitários engajados em movimentos sociais que foram alvo da pesquisa aqui apresentada indicam formas pelas quais sua formação política se beneficiou da transição pelos espaços distintos da universidade e do movimento social.

Então, esse sujeito político no caso, não político-partidário, [...] mas político no sentido, assim, de ir em várias fontes, várias bases ao mesmo tempo [...]. Mas, de outra forma, é tu ver que também tem uma certa cobrança também do movimento quando tu és uma pessoa, digamos, pública ou política - nesse sentido mais político dessas coisas - de que o tempo inteiro as pessoas te cobram, né? [...] e muitas vezes a universidade, os grupos da universidade me chamam pra discutir (BRENDA LEE).

Hoje em dia, não dá mais pra ficar em cima do muro, né? Ou somos de uma ideia de esquerda ou somos de uma ideia de direita, mas a gente precisa trazer essa opinião e posição pra dentro da universidade. E o movimento social negro, ele não é todo de direita e não é todo de esquerda. A gente precisa respeitar as especificidades de cada um e de cada uma [...], principalmente no momento que estamos vivendo aí, novamente. As transformações sociais a partir da implementação ou da não implementação das políticas públicas (DANDARA).

Eu acho que a primeira questão é que eu não vou estudar pra eu ter um emprego e ganhar cinco mil, dez mil, vinte mil por mês... Eu acho que isso é o fundamental, que na maioria das vezes a gente ouve de colegas que não estão inseridos nos MS: que esse é o objetivo final, é trabalhar pra receber um bom salário. E eu acho que, estando no MS, a gente está na universidade, mas a gente tem uma responsabilidade a mais [...]. Como que esse conhecimento, essa experiência de estar na universidade pode contribuir para a transformação da sociedade? Então, eu acho que essa é a principal importância da formação política: que a gente vem pra universidade com um outro olhar, que, de repente, antes de estar no MS, eu não tinha (ROSE).

Eu acho que a universidade tá mais democrática, tá mais aberta, essas questões de acesso são mais discutidas, as questões de sentidos, também, mas eu não sei até que ponto essa filosofia, essa forma de trabalhar, ela capilariza tanto, né? [...] Primeiro, o alunado mudou completamente; tá com uma cara completamente nova. Cada vez mais jovem. Cada vez mais mestres e doutores, doutoras se formando. E são essas pessoas que estão ocupando os espaços na universidade. [...] Mas 
atualmente, eu acho que a formação política, ela é secundária dentro da universidade. [...] Acho que nem são todos os alunos e alunas que conseguem perceber na verdade o tipo de universidade que estão vivenciando hoje. [...] O fato de ter me aproximado de outras ideias, de ter uma formação política mesmo no movimento, eu acho que me deixa mais sensível e mais atento a esse funcionamento: à hierarquização, à questão dos poderes, e como as coisas se articulam, como os espaços são compartilhados, quem tem direito ao quê [...]. Eu não quero fazer um trabalho pra manter o próprio sistema, ali. No mínimo, esse trabalho, ele tem que ter uma devolutiva social. Ele tem que ir pra rua. Ele tem que sair, ele tem que ter a ver com a vida. Essas aproximações de academia e vida, esse é o grande nó, ainda (JEAN).

Ah, foi fundamental, acho que fez a diferença, a militância. [...] A universidade foi só o lugar onde foi mais ainda concretizada uma postura política de esquerda que não concorda com as desigualdades, não concorda com a posição das mulheres, que é injusto no mundo. [...] Então, tu tinhas que fazer disputas de centro acadêmico, a disputa ideológica era muito forte. Isso fazia tu teres que te forjar, tu teres que ler. [...] A formação política é assim essa formação não só do ponto de vista teórico, mas do ponto de vista de você conseguir reconhecer o que é estratégico, o que é tático. O que é "vou lutar agora", o que é "vou lutar mais adiante". [...] o que eu me junto pra enfrentar - quem é o meu inimigo, né? E essa disputa ainda acontece. E eu acho que essa percepção vem por causa da formação política que eu tive. E continuo tendo. A gente sempre tem, né? Que a gente tá sempre se formando, na verdade. Ninguém tá pronto (PAGU).

Eu só fui pra universidade porque eu acreditava, e acredito muito, que o que as escolas faziam com os indígenas era errado. Então, por isso eu fui à universidade. $\mathrm{E}$, quando eu faço isso, eu tô tentando mostrar que tem outros caminhos pra universidade, pra nós enquanto indígenas, pra nós enquanto escola. [...] Naquela época, a identidade indígena tava morrendo, ela tava sendo apagada. E como é que você fortalece isso? Então, a partir dessa concepção eu fui pra universidade, fui buscando conhecimento que pudesse fazer com que eu refletisse isso (SEPÉ).

Eu sempre tentei fazer, e consegui, muitas vezes, uma interação entre esses dois mundos que aparentemente são muito distantes, mas na verdade não são tão distantes assim. [...] tem que diferenciar pauta social geral das expectativas do sujeito.[...] E eu tenho crença nisso, o senso comum é importante, vivência é importante, práticas são importantes, mas isso não substitui a ciência. Pode andar ao lado, pode não qualificar a ciência. Mas a ciência sem dúvida qualifica o senso comum, sem substituir (MARTIN).

Estar na universidade torna o sujeito do MS potencializado para o debate, para as proposições, pois agrega os conhecimentos teóricos encontrados na universidade, assim como as experiências vividas de participação e diálogos. Por outro lado, a participação no MS foi reconhecida pelos sujeitos como importante espaço de formação política por meio da luta social. O deslocamento entre espaços com diferentes códigos e expectativas impulsiona o "movimento do sujeito" e imbui a ação política de outras fecundidades ("vem pra universidade com um outro olhar", "fez a diferença, a militância", "conhecimento que pudesse fazer com que eu refletisse", "a ciência sem dúvida qualifica o senso comum"). 
Os sujeitos entendem que há mesmo certa radicalidade política na circulação por diferentes arenas ("ir em várias fontes"), expandindo a percepção da política para além das limitações do senso comum ("não político-partidário"), reconectando-a com sua organicidade e seu caráter inter-relacional ("várias bases ao mesmo tempo"). Desenvolvem sensibilidade ao quanto há de político na institucionalidade acadêmica ("à hierarquização, à questão dos poderes, e como as coisas se articulam, como os espaços são compartilhados, quem tem direito ao quê"). Percebem a injustiça que transpassa esse, entre tantos outros espaços ("não concorda com as desigualdades, não concorda com a posição das mulheres, que é injusto no mundo").

A posição social do sujeito político, sua inserção em determinadas instituições de visibilidade e prestígio social, como é o caso da universidade ("tu és uma pessoa, digamos, pública ou política"), implica em algumas responsabilidades perante os grupos a que pertence ("o tempo inteiro as pessoas te cobram"). Essas responsabilidades se tornam mais agudas em uma conjuntura que demanda posicionamento e ação política ("não dá mais pra ficar em cima do muro"). Da mesma maneira, a inserção no movimento social também apresenta cobranças ao sujeito ("a gente tem uma responsabilidade a mais"), que se ligam com uma perspectiva de compromisso histórico ("pode contribuir para a transformação da sociedade", "tem que ter uma devolutiva social"). Há, ainda, um processo de tomada de consciência de que o próprio trabalho acadêmico deve ser intencionalizado para uma mudança das estruturas sociais em que a política acontece (“aproximações de academia e vida, esse é o grande nó, ainda”).

Assim, parte da ação do sujeito político democrático é promover o fluxo das disputas entre as arenas ("trazer essa opinião e posição pra dentro da universidade"). Por um lado, isso pode ser visto como um recurso do repertório do sujeito político que circula pela universidade e pelo movimento social ("eu sempre tentei fazer, e consegui, muitas vezes, uma interação entre esses dois mundos"). Por outro, pode ser reconhecido como um movimento que pode partir de outros sujeitos inseridos nas próprias instituições ("os grupos da universidade me chamam pra discutir").

Os sujeitos reconhecem, ademais, que há espaços na universidade onde a disputa ocorre e qualifica a ação política do sujeito ("fazia tu teres que te forjar, tu teres que ler", "reconhecer o que é estratégico, o que é tático"). Investem, precisamente, nas contradições que a universidade, como espaço público, apresenta ao sujeito: se reproduz uma estrutura social injusta, também habilita o sujeito capaz de acessá-la a intervir nessa mesma estrutura ("eu só fui pra universidade porque eu acreditava, e acredito muito, que o que as escolas faziam com os indígenas era errado").

Esses sujeitos em movimento se deslocam, portanto, na perspectiva da potencialização de sua ação, predispostos a uma construção que alia conteúdos de diferentes espaços ("e como é que

\begin{tabular}{l|c|c|c|c|c|c|}
\hline () Rev. Educ. Perspec. & Viçosa, $M G$ & v. 9 & n. 3 & p.734-749 & set./dez. 2018 & eISSN 2178-8359 \\
\hline
\end{tabular}


você fortalece isso?"). Explorar contradições, como compor alianças, é especialmente importante naquelas fases do ciclo histórico em que se desafiam as conquistas democráticas ("principalmente no momento que estamos vivendo aí, novamente"). Nessas conjunturas críticas, e se encontrando em posição desfavorável, o sujeito político precisa lançar mão de importantes competências: capacidade de articulação agonista ("respeitar as especificidades de cada um e de cada uma", "eu me junto pra enfrentar") e de avaliação da forma pela qual os processos se desenrolam nos diferentes níveis ("as transformações sociais a partir da implementação ou da não implementação das políticas públicas", "diferenciar pauta social geral das expectativas do sujeito", "o que é "vou lutar agora', o que é 'vou lutar mais adiante"').

Entre as contradições a serem exploradas, está a ação sobre os limites das instituições para ampliar e aprofundar a democracia. Afinal, a experiência de formação universitária, por si só, não garante uma formação política ("na maioria das vezes a gente ouve de colegas que não estão inseridos nos MS: que esse é o objetivo final, é trabalhar pra receber um bom salário", "a formação política, ela é secundária dentro da universidade"). Por isso, desenvolver a universidade na perspectiva da concretização da cidadania demanda atentar para a importância de buscar incorporar no espaço acadêmico as contribuições de outros espaços formativos, de modo a fomentar as capacidades políticas dos sujeitos que tomam parte da universidade ("me deixa mais sensível e mais atento a esse funcionamento").

As falas dos sujeitos evidenciam que a formação política possibilita outro olhar sobre a realidade, a partir do qual o conhecimento acadêmico se torna ferramenta de luta. Tornar-se referência, assumindo posturas de luta e enfrentamento dos desafios desde o lugar de empoderamento representado pela universidade, é um recurso de potencialização do sujeito. De outra parte, assinalam germes de uma transformação universitária: a democratização da universidade a partir da inclusão de novos públicos possibilita uma renovação nas próprias perspectivas de democratização incorporados pela instituição ("universidade tá mais democrática, tá mais aberta"); a formação renovada com as cargas simbólicas de outros espaços formativos de subjetividades políticas representa oportunidades de avanço institucional na perspectiva da cidadania ("são essas pessoas que estão ocupando os espaços na universidade").

Afinal, como explicita Mouffe (2001), todas as relações sociais são passíveis de apropriação para agendas políticas. A formação de subjetividades políticas democráticas é a geração da consciência crítica que Ribeiro (1969) considera necessária para a elevação da universidade a novos patamares de funcionamento, coerentes com o movimento da sociedade. Ela se compõe também das sensibilidades éticas que Severino, A. (2012) afirma serem integrais à educação universitária, e que para Severino, F. (2011) estão na raiz da ação transformadora. É daí que os sujeitos políticos podem derivar a consistência e a propriedade que, conforme

\begin{tabular}{l|l|l|l|l|l|l} 
(C) Rev. Educ. Perspec. & Viçosa, $M G$ & v. 9 & n. 3 & p.734-749 & set./dez. 2018 & eISSN 2178-8359 \\
\hline
\end{tabular}


Genro (2011), são necessários para produzir consensos, seja pelo embate, seja pela concertação.

Há um espaço político interior ao indivíduo onde a formação se processa, onde acontece o "movimento dos sujeitos". O deslocamento entre espaços formativos provoca desequilíbrios que favorecem esse movimento, forçando-os a constantemente se reposicionarem diante da realidade e questionarem o lugar que ocupam. O sujeito que constrói sua identidade política entre espaços de formação distintas precisa organizar demandas à configuração de sua subjetividade - formas de apreender a realidade, julgar e agir - que são por vezes conflitantes. Mas a partir daí, pode também gerar alternativas, pluralistas e cidadãs, que emergem da consciência de sua própria incompletude e potencialidade. Como dizem os sujeitos, "tem outros caminhos pra universidade, pra nós enquanto indígenas, pra nós enquanto escola" (SEPÉ); “a gente tá sempre se formando, na verdade. Ninguém tá pronto” (PAGU).

\section{CONSIDERAÇÕES FINAIS}

A presença dos sujeitos em movimento na universidade é importante por trazer outros olhares, experiências e concepções de sociedade e de mundo. O sujeito em movimento ainda representa a possibilidade de rupturas com este modelo de sociedade e a construção de novos paradigmas societais, políticos e epistemológicos.

O conhecimento teórico, base da formação acadêmica, assim como as articulações, participações, reflexões e debates potencializam o sujeito político. Estas percepções estão de acordo com as proposições de Genro (2011, p. 146), ao afirmar que a universidade é atravessada pela pluralidade humana e que "essa compreensão nos permite tensionar os seus processos, suas práticas e o seu pensar no sentido da formação de sujeitos democráticos”.

Portanto, o desafio é fortalecer este debate em todas as áreas da universidade pública. Pensar na formação política é trazer sentidos para a construção do conhecimento que levem em conta o sujeito inserido em um espaço social, que sendo sujeito de ação pode transformá-lo (ARENDT, 2007). A consciência de uma ação transformadora sobre a realidade pode ser possibilitada e facilitada pela reflexão coletiva emergente no processo de formação.

Os resultados evidenciaram que a universidade pública pode contribuir significativamente na formação do sujeito político ao dialogar com a sociedade. Por outro lado, as falas evidenciam que a universidade pública ainda é um espaço onde padrões políticos conservadores coíbem o pleno desenvolvimento de uma cultura democrática, reproduzindo valores e modelos prédefinidos, muitas vezes resistentes às mudanças que possibilitariam a ampliação dos horizontes de cidadania.

\begin{tabular}{l|c|c|c|c|c|c|} 
() Rev. Educ. Perspec. & Viçosa, $M G$ & v. 9 & n. 3 & p.734-749 & set./dez. 2018 & eISSN 2178-8359 \\
\hline
\end{tabular}


A presença de estudantes engajados no MS, com suas formas de ação, provoca mudanças no modo de perceber questões específicas, experiências de organização, de democratização, de diálogos que desafiam a universidade a romper paradigmas. O desafio é construir uma perspectiva pluralista de universidade, ainda que se tenha que enfrentar resistências e desafios. O MS tem importante papel neste processo, tensionando, questionando e propondo alternativas e políticas no sentido de fazer acontecer o novo paradigma e tornar a universidade mais que pública, popular, democrática, promotora de um conhecimento contextualizado, que dialoga com a diversidade de formas de viver e de saber.

Precisamos reconhecer a universidade como espaço importante de formação que vem deixando marcas fortes e várias lideranças despontam de seus espaços e experiências. Ela é, portanto, espaço de formação de referência. E, como referência, suas experiências são mostradas e multiplicadas. Entre os desafios que se apresentam à universidade pública está a abertura a novos saberes que contribuem na formação de uma consciência social e política nos estudantes. Os novos olhares de/na universidade pública podem levar a rupturas viáveis que possibilitem a construção de novos saberes para uma sociedade que valorize a justiça e inclusão social, os direitos humanos, a democracia participativa. Ampliar o diálogo da universidade com o MS é um desafio, assim como levar esses debates para o processo formativo, potencializando uma formação de sujeitos com consciência social e política.

O diálogo que estabelecemos com os sujeitos da pesquisa nos permite afirmar que o "sujeito em movimento" provoca o "movimento do sujeito" e o desafio é que esse movimento se constitua não só em um movimento individual e dos coletivos, também precisa se desdobrar no nível institucional, da universidade. A expansão e democratização do acesso pode viabilizar a democratização dos processos políticos e epistemológicos. A diversidade de vozes e saberes contribuiria, assim, para a formação de uma subjetividade política capaz de confrontar as estruturas e propor ações para a construção da cidadania democrática.

\section{REFERÊNCIAS}

ARENDT, Hannah. A condição humana. 10. ed. São Paulo: Forense Universitária, 2007.

ARENDT, Hannah. O que é política? Fragmentos das obras póstumas. 11. ed. Rio de Janeiro: Bertrand Brasil, 2013.

BRASIL. Lei n. 12.711, de 29 de agosto de 2012. Dispõe sobre o ingresso nas universidades federais e nas instituições federais de ensino técnico de nível médio e dá outras providências. Presidência da República. Brasília: DF, 2012.

DOEBBER, Michele Barcelos. Indígenas estudantes nas graduações da UFRGS: movimentos de re-existência. 2017. 302 f. Tese (Doutorado em Educação) - Programa de

\begin{tabular}{l|c|c|c|c|c|c} 
() Rev. Educ. Perspec. & Viçosa, $M G$ & v. 9 & n. 3 & p.734-749 & set./dez. 2018 & eISSN 2178-8359 \\
\hline
\end{tabular}


Pós-Graduação em Educação, Faculdade de Educação, Universidade Federal do Rio Grande do Sul, Porto Alegre, 2017.

GENRO, Maria Elly Herz. Educação do sujeito político na universidade. In: LEITE, Denise; GENRO, Maria Elly Herz; BRAGA, Ana Maria e Souza. Inovação e pedagogia universitária. Porto Alegre: UFRGS, 2011. P. 139-152.

GIL, Antônio Carlos. Métodos e técnicas de pesquisa social. 6. ed. São Paulo: Atlas, 2008

GOHN, Maria da Glória. Movimentos sociais e educação. 2. ed. São Paulo. Cortez, 1994.

GOHN, Maria da Glória. Novas teorias dos movimentos sociais. 4. ed. São Paulo: Edições Loyola, 2012.

GOMES, Romeu et al. Organização, processamento, análise e interpretação de dados; o desafio da triangulação. In: MINAYO, Maria Cecília de Souza; ASSIS, Simone Gonçalves; SOUZA, Edinilsa Ramos de (Orgs.). Avaliação por triangulação de métodos. Rio de Janeiro: Editora Fiocruz, 2005. P. 185-221.

GRISA, Gregório. Ações afirmativas na UFRGS: racismo, excelência acadêmica e cultura do reconhecimento. 2015. 220 f. Tese (Doutorado em Educação) - Programa de PósGraduação em Educação, Faculdade de Educação, Universidade Federal do Rio Grande do Sul, Porto Alegre, 2015.

MINAYO, Maria Cecília de Souza. O desafio da pesquisa social. In: MINAYO, Maria Cecília de Souza; DESLANDES, Suely Ferreira; GOMES, Romeu (Orgs.). Pesquisa social: teoria, método e criatividade. 31. ed. Rio de Janeiro: Vozes, 2012. P. 9-29.

MOUFFE, Chantal. Globalização e cidadania democrática. Revista da Faculdade de Direito da UFPR, Curitiba, v. 36, p. 17-25, 2001.

RIBEIRO, Darcy. A universidade necessária. Rio de Janeiro: Paz e Terra, 1969.

RISTOFF, Dilvo. Democratização do campus impacto dos programas de inclusão sobre o perfil da graduação. Cadernos do GEA, Rio de Janeiro, n. 9, jan./jun. 2016.

SEVERINO, Antônio Joaquim. Integrar cultura e humanismo: desafio pedagógico da Filosofia no Ensino Superior. Educar em Revista, Curitiba, Brasil, n. 46, p. 21-35, out./dez. 2012.

SEVERINO, Francisca Eleodora Santos (Org.). Ética e formação de professores: política, responsabilidade e autoridade em questão. São Paulo: Cortez, 2011. 


\section{Sobre os Autores}

${ }^{1}$ Claudete Lampert Gruginskie - Técnica em Assuntos Educacionais na Secretaria de Avaliação Institucional. Mestre em Educação. E-mail: clau.gruginskie@ gmail.com - ORCID:

https://orcid.org/0000-0002-4782-5339

${ }^{2}$ Maria Elly Herz Genro - Professora Permanente no Programa de Pós-Graduação em Educação. Professora Associada do Departamento de Estudos Básicos. Doutora em Educação. E-mail: mariaellyh8@gmail.com - ORCID: https://orcid.org/0000-0002-3330-2158

${ }^{3}$ Bernardo Sfredo Miorando - Doutorando no Programa de Pós-Graduação em Educação. E-mail: bernardo.sfredo@gmail.com - ORCID: https://orcid.org/0000-0002-7556-1684 